\title{
Political Parties and Foreign Policy: A Structuralist Approach
}

\section{Citation}

King, Gary. 1986. Political parties and foreign policy: A structuralist approach. Political Psychology 7(1): 83-101.

\section{Published Version}

doi:10.2307/3791158

\section{Permanent link}

http://nrs.harvard.edu/urn-3:HUL.InstRepos:4320361

\section{Terms of Use}

This article was downloaded from Harvard University's DASH repository, and is made available under the terms and conditions applicable to Other Posted Material, as set forth at http:// nrs.harvard.edu/urn-3:HUL.InstRepos:dash.current.terms-of-use\#LAA

\section{Share Your Story}

The Harvard community has made this article openly available.

Please share how this access benefits you. Submit a story.

Accessibility 


\title{
Political Parties and Foreign Policy: A Structuralist Approach ${ }^{1}$
}

\author{
Gary King ${ }^{2}$
}

This article introduces the theory and approach of structural anthropology and applies it to a problem in American political science. Through this approach, the "bipartisan foreign policy hypothesis" and the "two presidencies hypothesis" are reformulated and reconsidered. Until now participants in the debate over each have only rarely built on, or even cited, the other's research. An additional problem is that the widespread conventional wisdom in support of the two hypotheses is inconsistent with systematic scholarly analyses. This paper demonstrates that the two hypotheses are drawn from the same underlying structure. Each hypothesis and the theoretical model it implies is conceptually and empirically extended to take into account the differences between congressional leaders and members. Then, historical examples and statistical analyses of House roll call data are used to demonstrate that the hypotheses, while sometimes supported for the congressional members, are far more applicable to leadership decision making. Conclusions suggest that conventional wisdom be revised to take these differences into account.

KEY WORDS: congress; foreign policy; leaders; political parties; presidency; structural anthropology

\section{INTRODUCTION}

Structural anthropology is a theory and an approach which has not often been considered or used in political science research. This paper in-

II appreciate the critical comments on an earlier version of this work by Gerald Benjamin, Leon D. Epstein, Barbara Hinckley, Herbert M. Kritzer, Beatrice L. Lewis, Ann McCann, and especially Richard M. Merelman. I am also grateful for the suggestions of the editor and anonymous referees.

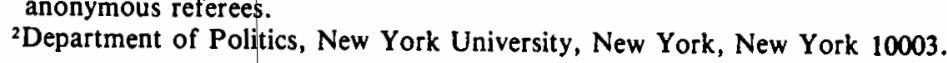


troduces structuralism and applies it to a research problem in American politics. One result is that this should make it easier for others to use the theory and approach in other areas of political science. Structural anthropology, as eloquently explicated by Lévi-Strauss $(1963,1966,1969)$ and others, implies several assumptions.

First, all of culture is divided into two categories: surface level or content and deep structure. Social scientists never observe more than the content, but we should, it is argued, always attempt to infer to the structures. The structuralist goal is to discover structures which underlie and determine a variety of surface level cultural phenomena.

Second, all structures take the form of binary oppositions, and all meaning is derived from these contrasts. The symbol "red," for example, does not mean "stop" without its contrast with the opposing symbol "green," and its associated concept, "go" (Leach, 1970). Social psychologists, for example, have long identified social groups primarily in relation to each other (Commins and Lockwood, 1979). Political scientists usually refer to power relationships with a vertical metaphor: as in up:down::superordination:subordination::upper class:lower class::"on your way to the top": "falling by the wayside."

Structural anthropologists sometimes go further and assume or assert that these binary oppositions are fundamental characteristics of the human mind, but although this assumption may be of academic interest, it is inherently unobservable and usually unnecessary for the analysis of the research problem being considered. Schwartz (1981: 159), for example, distinguishes between three levels of universality in dual classification. The most methaphysical are "formal universals," which include fundamental assumptions about the binary nature of human thought. In between, are "substantive universals, which are observable but do seem to exist in nature (e.g., hot-cold, left-right, up-down). Finally, there are "sociological universals," which are "the alignment of certain moral and social states to particular substantive contrasts." It is useful to add to Schwartz's hierarchy political universals, which I define as the alignment of certain political phenomena with the more basic substantive or social-psychological contrasts.

Third, Lévi-Strauss argued that it is unnecessary to examine all societies or to compare a variety of time periods to discover fundamental structures. For just as messages which we receive from different senses can be transformed into each other (e.g., visualizing a story), the past exists only as a structural transformation of the present. Thus, diachronic (overtime) and synchronic (cross-cultural) analyses are two ways of doing the same thinglooking for structure and, by so doing, uncovering important characteristics of human culture. 
By using a version of this structural anthropological approach, one which is unencumbered by many of its metaphysical assumptions, this paper identifies and examines two binary oppositions at the level of the political universal. ${ }^{3}$ The goal is not to learn about the formal universals of the human brain, but instead to learn about these two political oppositions and their relationships in American politics. Deep structure is of interest when we move from the political universals to the social-psychological and substantive universals in order to assist in understanding and explaining the surface-level relationships of concern to social scientists.

In the sections which follow, two binary oppositions existing in American politics are introduced. Relationships between the two are first explored with conventional assumptions. These assumptions, however, are found to be inconsistent with available scholarly evidence. A better explanation of the relationship between the oppositions is then presented along with supporting data. Finally, after arguing that one structural explanation underlies both oppositions, extensions to other surface-level phenomena are made. It turns out that structural anthropology provides a useful approach which helps uncover relationships between several literatures rarely considered together, but which are in fact inexorably related and beneficially combined. As a result, newly hypothesized relationships among several data sets are derived. The data, in turn, provide the first systematic evidence of several important theoretical relationships.

\section{THE REPUBLICAN/DEMOCRATIC AND FOREIGN POLICY/DOMESTIC POLICY BINARY OPPOSITIONS}

The two binary oppositions considered here are the distinctions between the parties and between two categories of public policy. Consider first the oppositions between the Democratic and the Republican parties. Clearly this binary categorization exists in most parts of the American culture: For the average citizen, to be identified with the Democratic party is to generally prefer more liberal positions. To be elected as a Republican is, in general, to take more conservative issue stands.

Republicans and Democrats meet in different national, state, and local conventions to choose a variety of party candidates; they vote for different candidates in different primaries or caucuses and sit on different sides of an aisle in both houses of congress, in all but one of the state legislatures,

${ }^{3}$ Although only U.S. culture is considered, the oppositions introduced below can be extended to other nations using slightly more general terminology. 
and in thousands of local (city, county, town, etc.) governments. For example, "Social Identity" is defined by Tajfel (1982: 24) as "that part of the individuals' self-concept which derives from their knowledge of ... membership [in] a social group... together with the value and emotional significance of that membership." For of ficeholders social identity refers directly to their party identification.

Although the Republican/Democratic distinction is clear enough to give parties separate meanings, the boundary between the two is not well defined. Rates of split-ticket voting, "roll-off," and "drop-off" (Burnham, 1970) are high; the proportion of the electorate identifying with a political party is far from complete; of those who do identify with a political party, variable numbers vote in accord with their party (Crotty and Jacobson, 1980); party identification is volatile, as are aggregate election returns; legislators rarely use their party membership as the sole cue for voting decisions (Clausen, 1973); and even the ideological distinctiveness of aspects of the parties seem to have declined.

In sum, the boundary between the parties is crossed easily and often, and can be considered "loose" [see Leach (1976: 33-36) for a definition of a 'boundary' and Merelman (1984) for examples and definitions of the concept as it is used here]. But even though the boundary is looser, the party distinction is far from being lost. In the general case, Allen and Wilder (1975) find that even when group beliefs are similar, the minimal process of in and out group categorization is enough to make in group favoritism persist (see also Billig and Tajfel, 1973; Sole et al., 1975). In fact, there is even some counter-intuitive evidence that when groups have similar values, intergroup discrimination is actually heightened-plausibly in order to protect group distinctiveness. So, party boundaries are weakening but do not seem in danger of losing their meaning.

The second binary opposition to be considered here is the distinction between the American "bipartisan" approach to foreign policy and the partisan approach to domestic policies. It is an often stated aspiration to keep politics out of foreign policy, in both congressional deliberations and public discussion. "Politics stops at the water's edge," it is often written (Bliss and Johnson, 1975). This distinction guarantees that even when politics is part of foreign policy decisions, it is usually within the rhetorical constraints of bipartisanship. The boundary between the way citizens and leaders deal with foreign and domestic policies may not be as strong as it once was, but it does exist and is clearly relevant.

There is a large body of social-psychological work which may partially explain the existence of these oppositions in terms of in group/out group distinctions. For example, Stein (1976) finds in a review of empirical literature from several disciplines that inter-group "conflict does increase internal cohesion under certain conditions." Tajfel (1982) finds agreement with this pro- 
position from, among others, Freud and early frustration-aggression theorists. Other consequences of in group/out group conflict for which Tajfel cites evidence include the increased "positive evaluation of the ingroup or its products."

For the Democratic/Republican opposition, the most pronounced cognitive and attitudinal distinctions are likely to occur when the parties try to change the status and power of each other (Brown and Ross, 1982). Relevant examples of accentuated party distinctiveness, out group discrimination, and heightened levels of inter-party verbal combat include legislative motions for which the president or other leaders of the parties have their reputation at stake, electoral campaigns in which there is an attack on the very existence of the opposition group, and in debates in which the parties attack fundamental principles on which the opposition makes its case.

A major paradox of these two oppositions is that the same political actors who are pushed apart by the party opposition are pulled together on foreign policy matters. We will see that for party leaders, these cross-pressures are exaggerated. One of the contributions of this paper, therefore, is to suggest a framework for understanding this problem.

\section{OPPOSITION SIMILARITIES}

Traditionally, these two oppositions have been treated separately or as only partially related; after ail, they are prima facie different phenomena. But can they be usefully studied together? Are the two binary oppositions related? And if they are, what form does the relationship take? Guided by structuralism, alternative answers to these questions are now explored.

One conventional and clearly plausible connection is that referred to by Cecil V. Crabb (1957: 198), and mentioned by many others: "The two important factors that normally may be expected to favor the achievement of bipartisan cooperation in foreign affairs are the nonideological nature of American parties and the absence of strict party discipline in congress." Put differently, when there is less partisanship (i.e., weak boundaries between the parties), bipartisanship in foreign policy is easier to achieve. The hypothesis is that when the definitional, attitudinal, and behavioral boundary between the Republican and the Democratic parties breaks down, the boundary between foreign policy bipartisanship and domestic policy partisanship becomes tighter and less permeable; that is, partisan politics would be less likely to cross the boundary and infect foreign policy decision-making. That Professor Crabb refers to the loose party boundary by its "nonideological" nature emphasizes that this cultural code is very different from tightly-bounded codes, such as ideology or religion. 
Although this statement of the relationship between the two oppositions is theoretically reasonable, it is not supported by a variety of evidence. Consider three contradictory historical and cross-sectional examples.

First, although there is considerable evidence that American political parties are becoming more permeable, loose, and porous (Crotty and Jacobson, 1980), there is also evidence - or at least widespread expert opinionthat partisan politics are increasingly infecting the foreign policy arena. As evidence, consider Chace (1978) as representative of scholarly, journalistic, and other opinion: "The kind of broad consensus that obtained during the postwar era and which became a shibboleth of American foreign policy may no longer be possible short of war."

Consistent with this is a dramatic increase in suggestions of how to tighten the foreign-bipartisan/domestic-partisan boundary. These proposals include creating ad hoc bipartisan groups in congress to follow important foreign policy issues (Hamilton, 1978), increasing congressional expertise (Rourke, 1977), establishing committees of the president's cabinet and members of congress (Manning, 1977), increasing politically responsible behavior from America's leaders (Bax, 1977), and having the president act in ways which would encourage party leaders in congress to work more closely together on foreign policy issues (Frye and Rogers, 1979). Of course, direct empirical analyses would be better evidence of this point, but none exist. ${ }^{4}$

Therefore, in this historical example, the strength of the boundary in each of the two binary oppositions seemed to vary together-loosely defined boundaries between foreign and domestic politics being more likely when there are loosely defined parties. The initial hypothesis of an inverse relationship, although consistent with conventional wisdom, is not supported in this first example.

As a second example, consider two types of people generally distinguished by socioeconomic levels (with education weighted heavily in the distinction). Most analyses have shown political parties to be more salient to those in the upper SES groups; these groups are more polarized along partisan lines and are more likely to identify with, and be active in, a political party than lower SES groups (Ladd and Lipset, 1971; Ladd with Hadley, 1978).

However, upper SES groups are also more likely to support a bipartisan foreign policy and to prefer bipartisan foreign policies. For example, John Mueller (1973: Ch. 5) identifies a "follower mentality" as characterizing people who, "take as cues for their own opinion [on war in particular and on foreign affairs in general] the issue position of prominent opinion

There is much research which could usefully establish this relationship. One example might be to content analyze samples of debates on the House and Senate floors on foreign and on domestic policy issues. Levels of conflict could then be compared and assessed. 
leaders," especially the president. Mueller's survey analyses clearly show that higher SES groups have higher proportions of "followers."

It may seem somewhat contradictory that those in upper SES groups are both more partisan and more likely to be "followers," particularly since the particular path on which they are following the leader may not be consistent with their relatively strong partisan predispositions. However, someone with a clear understanding of the differences between the parties is likely to understand when this boundary should be breached, and would therefore be more likely to support such an action under appropriate circumstances.

Thus, in this second example, for those groups in which the Republican/Democratic boundary is tight, the bipartisan foreign policy/partisan domestic policy boundary is also tight. This is additional evidence against the original hypothesis; the oppositions do seem to vary together.

As a final example, consider the differences between members and leaders of the House of Representatives. Since leadership in the House is solely based on the political party distinctions, it is a safe assumption that the Republican/Democratic boundary is tighter for the leaders than the members. The question then concerns the salience of the other opposition to these two groups; the proposition above indicates that this boundary is tighter for the members, while the two previous examples suggest the reverse. Establishing this latter possibility-that the porousness of the Republican/Democratic boundary varies in the same direction as the foreign/domestic policy boundary-would provide the first systematic evidence of this "bipartisan foreign policy" hypothesis, in this paper or in the literature.

With roll call data from the first session (for comparability) of each of five post-presidential election congresses (1961-1977), this question can be explored. By including those votes on which the president took a public position (see Congressional Quarterly) and using the representative's vote as the unit of analysis, those roll calls in which a larger proportion of representatives voted are weighted more heavily. Although some representatives might avoid controversial ("important") votes, a cursory examination of roll calls indicates that this weighting is generally in accord with conceptual importance.

A potential problem with the analysis is the clustering of observations by representative and by roll call, possibly causing an underestimation of the standard errors. However, because the data set is so large $(154,709$ voting decisions), all of the standard errors are very small, and a correction is therefore not likely to change this appreciably. ${ }^{5}$ Also, since many decisions in congress are concluded long before or entirely without a formal roll call, 
there may be a selection bias (see Barnow et al., 1980). Finally, because only the first congressional session of each presidency was used, honeymoon effects (Manheim, 1979) may cause problems. However, because these analyses are not closely related to a possible honeymoon effect, it is unlikely to greatly alter the results. Further analysis of other sessions would nevertheless be very useful. Qualifications aside, these data remain among the best which are available at present to analyze these questions.

In order to facilitate comparison, all equations explain the probability of voting with the president, and all control for the effects of region (north/south), party leadership, "In" (i.e., president's) and "Out" (i.e., opposition) party membership (Republican/Democratic party differences are not very strong in comparison to In/Out party differences), issue area, president, and time period. The consequence of this procedure is to take into account several plausible rival hypotheses about voting with the president. ${ }^{6}$ The model is a logistic analysis of tabular data. In party members are expected to support the president more than Out party members. In the case of bipartisan decision-making, the In/Out party split in support of the president is hypothesized to be greater on domestic than on foreign policy decisions.

In order to allow for the possibility that there is more variation within the broad categories of domestic and foreign policy than between them, there are three foreign policy and four domestic policy categories of roll calls. This coding of policy categories is consistent with varied results from separately conducted studies [see Kessel (1974) and Clausen (1973) for similar domestic codings and Hughes (1978) for similar foreign policy codings)].

The figures are presented with all years (1961-1977) combined because preliminary analyses indicated that similar relationships generally hold up over time and because of the benefits of saving space and reducing complexity. Figure 1 presents the predicted values of a logistic equation explaining the probability of the party leader voting with the president. ${ }^{7}$ Estimated probabilities for the In and Out parties across the seven policy areas appear in the Figure. The larger the difference between the In and Out parties for a particular policy area (the vertical distance between the lines in the figure), the stronger are the party boundaries for that policy area.

The first thing to notice about Figure 1 is that, as expected, In party members of the House of Representatives (the top line in the figure) support

${ }^{6}$ Including these statistical controls substantially reduces the possibility that leaders and members who vote with the president do so by coincidence rather than design.

The formal leadership of each party are the only real leaders in congress. For this analysis, only the highest ranking leader from each party who votes is considered. If the top three leaders do not vote (excluding the Speaker, who by tradition votes only in the case of a tie), the roll call is excluded from the analysis. 
the president far more often than Out party members (the lower line). But Figure 1 also indicates that except for defense policy - which could plausibly be explained by Vietnam becoming more of a domestic than a foreign policy issue (which, incidentally, supports the first example, above)-there is a striking difference in leadership support for the president: In foreign policy, the probability of an In party congressional leader supporting the president is about 25 percentage points more than Out party leaders (excluding defense). However, this split in party leadership support for the president is about twice as great in the four domestic policy categories. Thus, among the party leadership, there is a clear difference, a very tight boundary, between politics in foreign policy-which tends to be bipartisan-and politics in domestic policy - which tends to be partisan. This is witnessed by the clear distinction between the left and right sides of the figure.

In a parallel presentation, Figure 2 displays the same data, but for the general membership of the House. The difference between the two figures is dramatic: Among the members there is considerably less distinction (i.e., looser boundaries) between foreign and domestic policy decision-making (i.e., between the left and right sides of the figure). There is, however, still

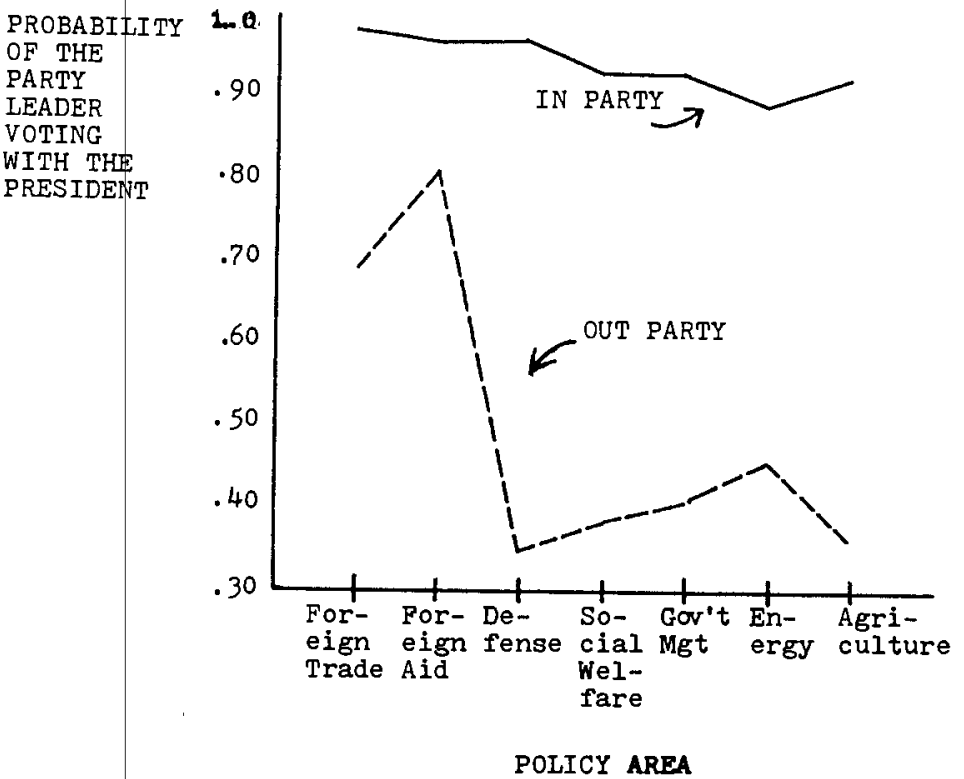

Flg. 1. In and Out party leadership support for the president. Source: Percentages computed from the PM,MI logit model. d.f. $=48, G^{2}=10667.35$. Note: For all figures, model abbreviations are as follows: Issue or policy area (I), President $(\mathrm{P})$, Party Leader's position (L), and party membership (M). 
some relationship. For example, on voting for foreign aid decisions there is on the average no In and Out party difference in the probability of a representative voting with the president. In contrast, in the government management category, In party members are about ten points more likely to vote with the president than Out party members. But although the differences are in the correct direction, the boundaries are nowhere near as tight as for the party leaders represented in Figure 1.

Thus in this example, as in the previous two, the two binary oppositions tend to vary together: When the Republican/Democratic boundary is tight (as for the party leaders), the Foreign-Bipartisan/Domestic-Partisan boundary is also tight. When there are somewhat weaker party distinctions (as for House members), there are also looser distinctions between types of politics (bipartisan or partisan) in different policy areas (foreign or domestic). It is clear that an alternative explanation is needed.

\section{TWO BINARY OPPOSITIONS - ONE UNDERLYING STRUCTURE}

The initial proposition was that the two codes varied inversely: When the boundary between one was tight the other should be loose. This

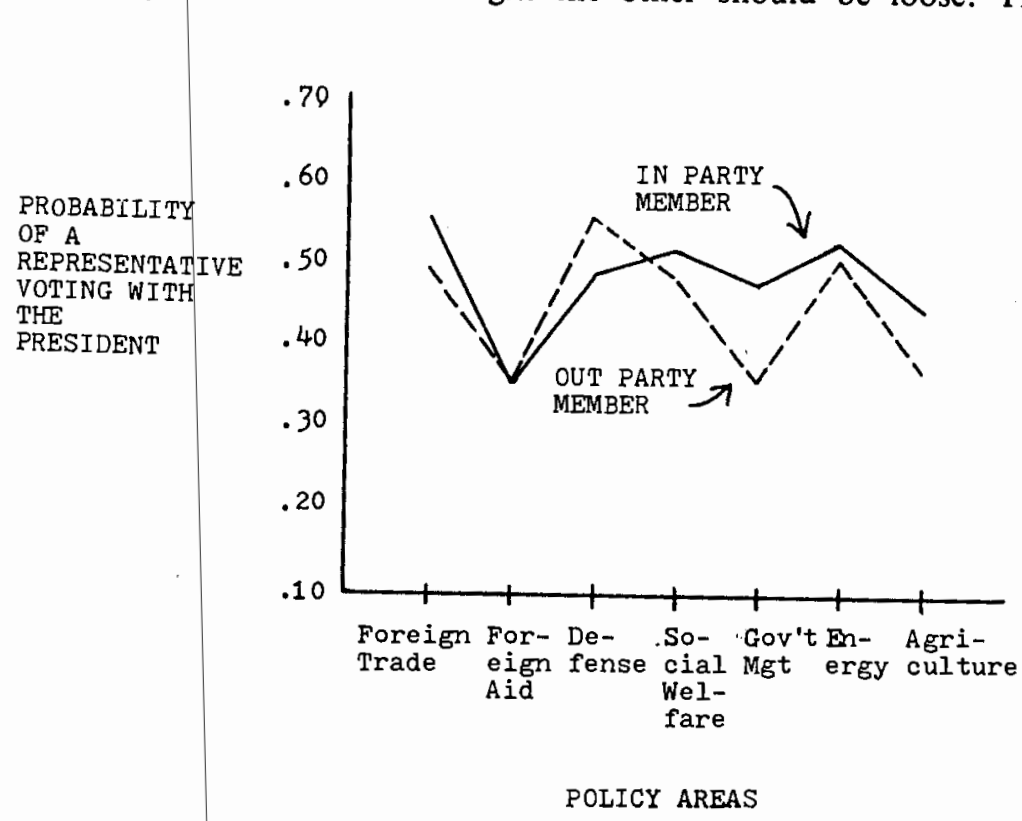

Fig. 2. In and Out party representatives' support for the President. Source: Percentages computed from the PLM,MI logit model. d.f. $=108, \mathrm{G}^{2}=4982.28 ; \mathrm{MI}$ component: d.f. $=6, G^{2}=315.17$ 
proposition - although not extensively explored in the literature - was supported by plausible argument and conventional political science wisdom. It appears as comments in scholarly articles and as a "well known fact" in many textbooks. However, empirical evidence from three examples demonstrated that this was probably not the case. Rather, the boundaries between the codes seemed to vary together - when one code was loose, the other code was loose as well. This leaves us with evidence of a relationship but with no explanation.

In order to derive an explanation, it is important to recognize that implicit in the discussion thus far is that each of these binary oppositions is a signal or metaphoric symbol for the other. It was implied that the oppositions varied together or apart or that one caused the other. An alternative formulation, and the basis for the explanation to be offered, is that the two oppositions are metonymic; they are contiguous to each other. In other words, one binary opposition is a structural transformation of the other: One fundamental structure underlies both distinctions.

The common structural basis for these two codes is the distinction between "we" and "they" (or, more generally, between "same" and "different;" the former are used because they have more direct relevance to the surfacelevel relationships of interest). The concept of "we" does not have meaning until the opposing concept of "they" is contrasted and defined. This distinction is recognized in many areas: For example, David Truman's "Wave Theory" of interest group formation is based on this distinction: "Organization begets counterorganization," he writes (Truman, 1956). Implied is that without the original organization, the counterorganization would not have defined itself as a group (as "we") without the first group forming (and identifying themselves as "we" and everyone else as "they").

The same principle can be applied to Middle Eastern politics: Concomitant with the sharp increase in immigration of Jews to Palestine earlier in this century and their self-identification as "we," and others as "they," was the self-definition of the Arabs living in the area as "we," and the Jews as "they" (Safran, 1978); efforts at linguistic distinctiveness also increased during this period (Seckback, 1974). War, for example, could not exist without the we/they opposition.

There are, of course, many political phenomena which do not derive from a we/they distinction, as when political action is based on a sense of community or consensus. In the first presidential elections, for example, political rhetoric emphasized that the political party to whom the speaker belonged best represented, or in fact actually was, the will of the nation. John Anderson's 1976 "National Unity Party," and Reagan's 1984 appeal for a "new patriotism" are more recent examples.

The current Democratic/Republican opposition can be reformulated in this manner as "my party/other party," and the ForeignBipartisan/Domestic-Partisan binary opposition can also be viewed as 
redefining the we/they distinction. Instead of the division being between parties, it is between the U.S. and the world (or between the U.S. and parts of the world). From this perspective, these two oppositions are really surfacelevel (or content) manifestations or transformations of the same we/they structural opposition.

Thus far a relationship - the binary oppositions varying together - and an underlying explanation - a structural identity - have been assembled. But although deep structure is of academic and exploratory interest (and remains entirely an inference), it is the political content as presently conceptualized that is more often of interest to political scientists. These findings must therefore be related back to the original substantive problem. ${ }^{8}$ In sum, why is this structural relationship of interest?

The basic observation is that strong and clearly defined political parties lead to the bipartisan operation of foreign policy and the usual partisan operation of domestic policy. The explanation follows directly: With "strong" parties, that is with a strong we/they opposition, there is the possibility of an agreement between the party leaders; the leaders can speak more confidently for their party members and can make compromises with opposition party leaders more easily. ${ }^{9}$ Furthermore, bipartisanship (i.e., interparty agreement) is most likely when the issue defines the we/they opposition as the United States versus other nations; of course, bipartisanship is possible in other issue areas, but it seems likely to be most frequent in foreign policy. Thus, a strong, well-defined Republican/Democratic distinction leads to clearer boundaries between foreign policy bipartisanship and domestic policy partisanship. Based on systematic evidence, this effectively redefines the bipartisan foreign policy hypothesis.

\section{STRUCTURAL EXTENSIONS}

There are numerous (surface-level) manifestations of the structural we/they binary opposition. Examples from Truman's wave theory of interest group formation and from Middle Eastern politics have already been provided. Wide varieties of other applications could be explicated in considerable detail. For a few short examples, consider: Explanations of social group solidarity; arguments for the psychological and sociological necessity of the

${ }^{8}$ Lévi-Strauss might have been satisfied here, but for present purposes, I concentrate on using structural anthropology to understand the surface-level phenomena of primary interest to political scientists.

'On evidence for those circumstances when inter-group competition does not lead to in group cohesion. See Tajfel (1982: 16); Rabbie and deBrey (1971); Rabbie and Wiikens (1971); Rabbie and Huygen (1974); Rabbie et al. (1974); and Horwitz and Rabbie (1982) 
family or its surrogates; understanding ethnocentricity and racism; explorations of the origins of the nation-state; explanations of the development of the political party; the loyalty for certain products which some advertising creates; the appeal of sports and loyalty to certain teams (which are not coincidently named for local products and cities); and the tremendous appeal of the Olympics (one television network titles some events as "The U.S. verses The World"). The list could be extended. Instead, the approach suggested by this structuralist method in this paper is limited to examining one political issue related to the original two binary oppositions.

Another surface level manifestation of the we/they binary opposition is the institutional rivalry between congress and the presidency in the conduct of foreign policy. This binary opposition suggests that in foreign policy legislators are more likely to cross the opposition boundary to support the president. In domestic policy, however, the congress/presidency boundary becomes more salient and support for the president should drop.

Thus far, party, policy, and institutional oppositions on the level of political universals have been identified. All three seem to be related to the same social-psychological structure. Crabb (1957:7) describes some of the distinctions between these:

While the two problems - relations between the parties and relations between the executive and legislative branches - are intimately connected, only confusion can result from regarding them as identical problems. Harmony may prevail between the two branches of government concerned with foreign affairs; but this fact alone will not guarantee bipartisan co-operation in the foreign policy realm. (Crabb, 1957: 7)

The question of boundaries between the House and the presidency is explicitly addressed by Polsby (1968). An institutionalized organization he argues is, inter alia, "relatively well-bounded, that is to say, differentiated from its environment." An increase in this boundedness or institutionalization is clearly observed by a decrease in the turnover of members, increase in the average length of service, increase in the seniority of successful candidates for Speaker, and sharp decline of lateral career movement, in and out of the House and, in some notable cases, also in and out of the speakership. Thus, there has been, over time, a clearer we/they distinction between congress and the presidency.

From the conclusion above that the strength of the boundaries vary in the same direction, the stronger boundary between congress and its environment, and thus between congress and the presidency, should lead to an increased possibility of agreement between the two branches of government; this agreement should be most apparent in foreign affairs - where the we/they opposition is reformulated to provide incentive for congressional/presidential consensus.

It should be noted that the congress/presidency distinction is an institutional opposition, whereas the others are cognitive or social oppositions. The 
congress/presidency opposition probably originated on the basis of cognitive oppositions relevant to the founders, but this institutional distinction, once in place, probably encouraged and exaggerated the we/they cognitive opposition. The distinction blurs when considering political parties which, although never a formal part of American government, have been insitutionalized since its inception.

Although the congressional/presidential boundary is clearly becoming tighter (Polsby, 1968), it is not apparent from the literature whether in foreign affairs this has resulted in the predicted increase in agreement between members of congress and the president. What is of ten called the two presidencies literature [based on the hypothesis by Wildavsky (1966)] is far from consensus on either the level or the trend of congressional support for the president on foreign versus domestic affairs. In fact, even given the plausible case Wildavsky makes for it, there exists no satisfactory systematic evidence of this hypothesis. (It is interesting that published work in the two presidencies and bipartisan foreign policy literatures rarely cite each other or build on each other's work. The structuralist approach employed here helps make this connection.)

For example, LeLoup and Shull (1979) update Wildavsky's analysis and appear to find support for his thesis that congressional support for the president is greater on foreign than on domestic affairs but find that the relationship is not as strong in recent years. The problem with this analysis, and with Wildavsky's original article, is that their measure of support is no longer being compiled by Congressional Quarterly because of what CQ calls its "dubious quality." Lee Sigelman (1979) uses a different measure and finds no appreciable difference between foreign and domestic support. For potential problems with the Sigelman study see LeLoup and Shull (1980).

In order to provide a more systematic examination of this question, the data analyzed in Figures 1 and 2 can be examined further. Again data are presented for the members and the party leaders. The hypothesis is that as a consequence of the tight boundaries between congress and the president, both the leaders and members will support the president more on foreign than on domestic affairs roll calls. Furthermore, from the effects of stratification observed above, the relationship should be stronger among the leaders than the followers.

Figure 3 reports predicted values of a logistic equation explaining the probability of the party leader voting with the president for each of the seven policy areas. It suggests that, with defense policy as a possible exception again, leadership decisions on foreign affairs are far more likely to be supportive of the president than are decisions on domestic affairs. The difference is also striking: The probability of a congressional leader of either party voting with the president approaches certainty for foreign affairs but remains a full 25 


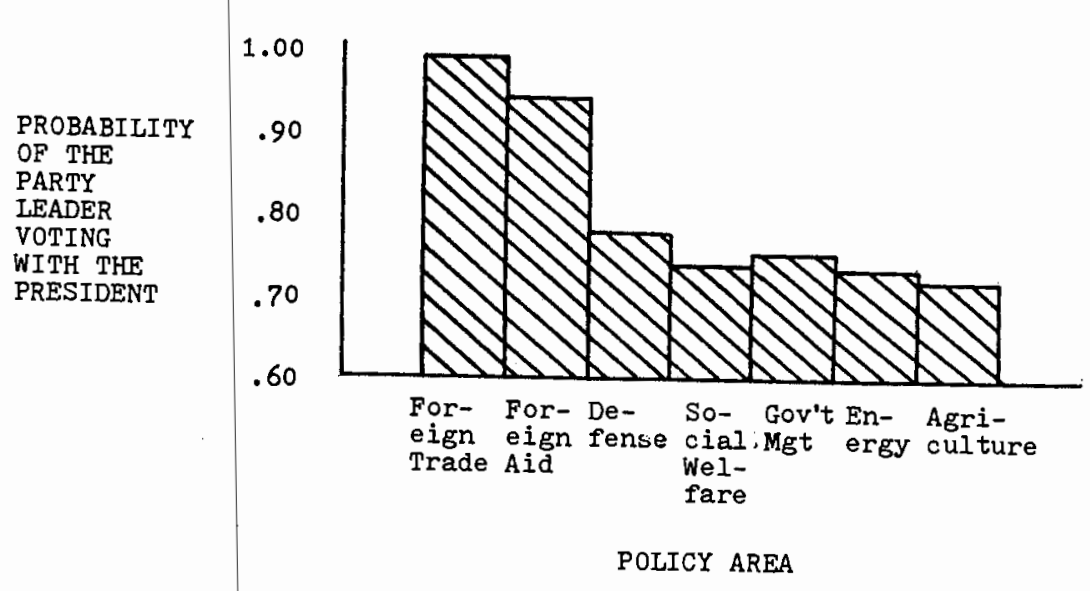

Fig. 3. Party leadership support for the President. Source: Percentages computed from the PM,I logit model. d.f. $=9, G^{2}=11940.89 ; P M$ component: d.f. $=9, G^{2}=54313.98$.

percentage points lower for domestic policy decisions. Support for the president is somewhat higher in foreign trade than foreign aid, and there is some variation in support among the domestic policies, but, again except for defense, the primary distinction is between foreign and domestic policies.

Thus, among party leaders in the House, the two presidencies thesis is well supported: With foreign policy comes a greater probability of leadership agreement with the incumbent president.

Figure 4 provides a parallel analysis for the general membership of the House. As is apparent, the probability of a representative voting with the president is not substantially different between foreign and domestic affairs. In fact, the weakest support for the president is in a foreign policy area (foreign aid). While this is consistent with the argument that those higher in American's stratification hierarchies tend to support tighter boundaries, it does not support the present argument.

To review: It was initially hypothesized from previous examples that more clearly defined boundaries between "we" and "they" should result in more intra-group cohesion and thus a greater possibility of we/they agreement on important (in this case foreign policy) issues. For executive-legislative relations, this generalization remains accurate for the party leadership but not for the general membership. Therefore, although the party leadership fit nicely into the structural explanation presented thus far, the members can only be considered an exception.

A possible explanation of this exception can be found in a closer examination of historical changes in congress. It has already been observed that congress has steadily become more bounded from the presidency (and 


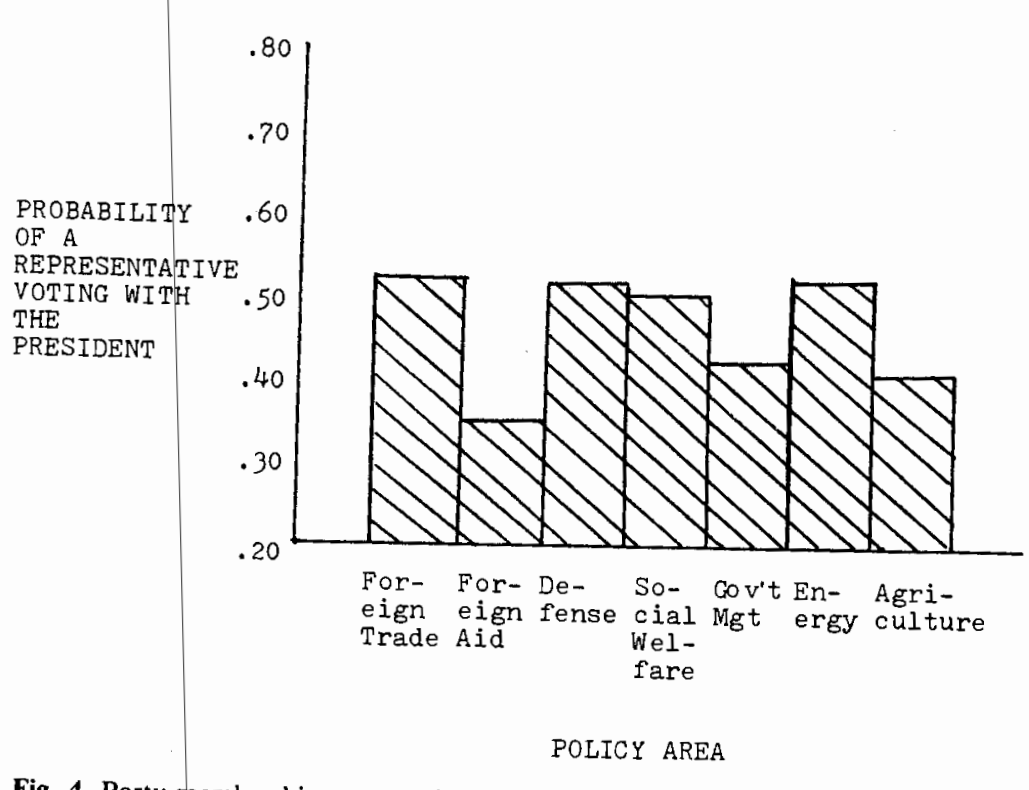

Fig. 4. Party rmembership support for the President. Source: Percentages computed $\mathrm{G}=39665.76$.

the rest of its environment). This trend can easily be seen as resulting, in part, from a greater presidential involvement in the legislative process (Davidson and Oleszek, 1981: 36-9; Wayne, 1978: 8, passim). In other words, as a method of protecting itself from presidential hegemony, congress has set up institutional procedures which emphasize decision-making decentralization. One indication of the probable consequence if congress had become more centralized is the greater support for the president among the formal party leadership: Centralization would give the leaders more influence, which in turn, would probably promote presidential dominance. The current "strategy" of decentralization - one of divide or be conquered - preserves congressional prerogative. Barbara Hinckley (1978: 206) provides several important illustrations of this argument:

The seniority system creates a committee leadership independent of party leaders including the president. Specialization in committees and subcommittees can generate subgovernments impenetrable to presidential influence. Midterm elections counter subgovernments impenetrable to presidential influence. Midterm elections counter
the effect of Presidential coattails from the preceding election, cutting back after two years of a four-year term the first full strength of a president's partisan support.

While the institutions and groups mentioned above become very cohesive in the face of stronger boundaries (e.g., what unites the country better than a good war?), clearer boundaries in the we/they distinction have, 
in the congressional example, discouraged intra-group cohesion. Always jealous of its power and position, congress took the logical approach (whether intended or not) of decentralizing and, as a result, reducing presidential influence. That is, "because there are fewer members who can influence large numbers of their colleagues, the number of points at which presidents must attempt to influence the congress is...that much more." (Davis, 1979). Therefore, the result of stronger boundaries, in this case, is less presidential influence in congress and less institutional agreement.

\section{CONCLUSIONS}

In the language of structural anthropology, deep structure, in the form of the we/they binary opposition, seems to have been identified. Several surface-level (i.e., content rather than structural) manifestations have been explored and explained. Reminiscent of Lévi-Strauss' elaborate contingency tables expressing underlying structure in terms of all possible combinations of cultural artifact, this analysis also found that the translation process from structure to surface-level phenomena has not been uniform.

Profound historical changes in, and dynamics of, political parties, congressional-presidential relations, bipartisanship verses partisanship, and policy area effects can all be usefully understood within this framework. More formally, structural analogies between the following have been established: we:they::Republican:Democrat::foreign policy:domestic policy::congress:president. When the boundaries between any of these pairs is strong, the boundary between any other pair is also likely to be strong.

This approach has also helped to connect and relate two literatures the "two presidencies" and the "bipartisan foreign policy" literatures - with currently few cross-references but with numerous substantive and structural relationships. This paper has demonstrated some of the benefits of considering these two literatures simultaneously.

The approach has also led to theoretical justification of and systematic evidence for both the bipartisan foreign policy and the two presidencies hypotheses. An analysis of more than one hundred and fifty thousand voting decisions from five presidential terms sometimes supports both hypotheses, but the relationship is substantially stronger among the leaders than among the members of the U.S. House of Representatives. Thus, conventional wisdom - which may be based more on this highly visible group - is more plausible when separate hypotheses are applied to congressional leaders and members.

The analysis has also helped to clarify the unique position of the party leadership in congress - cross-pressured at the intersection of two structural 
oppositions. The congress/presidency opposition encourages the leaders to side with congress and against the president. It suggests that the leaders resist presidential attempts at persuasion and protect congressional prerogative. However, the Republican/Democratic opposition pushes these leaders in a different direction. For in decentralized organizations such as the U.S. congress, information is power; so, to acquire information and perhaps a presidential endorsement of favored policy objectives, the leaders have incentives to associate with the president. This association gives the leaders more of a presidential perspective than other members - which results in far greater support for the president by the leaders than by the general membership. Being a leader in the U.S. House, then, has consequences for cognition that being a member does not have. The result for the party leadership is a difficult position and an ambiguous role.

\section{REFERENCES}

Allen, V. L., and Wilder, D. A. (1979). Group categorization and attribution of belief similarity. Small Group Behavior 110: 73-80.

Barnow, B. S., Cain, G. G., and Goldberger, A. S. (1980). Issues in the analysis of selectivity bias. Evaluation Studies Review Annual: Volume 5. Stromsdofer, E. W. and Farkas, G. (eds.), Sage Publications, Beverly Hills.

Bax, F. R. (1977). Legislative-executive relations in foreign policy: New partisanship or new competition? Orbis. 20 (Winter): 881-904.

Billig, M., and Tajfel, H. (1973). Social categorization and similarity in intergroup behavior Eur. J. Social Psychol. 3: 27-52.

Brown, R. J., and Ross, G. F. (1982). The battle for acceptance: An investigation into the dynamics of intergroup behavior. In Tajfel, $\mathrm{H}$. (ed.), Social Identity and Intergroup Relations, Cambridge Univ. Press, Cambridge.

Burnham, W. D. (1970). Critical Elections and The Mainspring of American Politics, Norton, New York.

Bliss, H., and Johnson, M. G. (1975). Beyond The Water's Edge: America's Foreign Policies, Lippincott, Philadelphia.

Chace, J. (1978). Is a foreign policy consensus possible? Foreign Affairs (Fall): 1-16.

Clausen, A. R. (1973). How Congressmen Decide: A Policy Focus, St. Martin's Press, New York. Commins, B., and Lockwood, J. (1979). Social comparison and social inequality: An experimental investigation in intergroup behavior. Brit. J. Soc. Psychol. 9: $281-89$.

Crabb, C. V. (1957). Bipartisan Foreign Policy: Myth Or Reality, Row, Peterson, and Co. Evanston, IIl

Crotty, W. J., and Jacobson, G. C. (1980). American Parties in Decline, Little, Brown, Boston. Davis, E. L. (1979). Legislative reform and the decline of presidential influence on Capitol Hill. Brit. J. Pol. Sci. 9 (October): 456-479.

Davison, R. H., and Oleszek, W. J. (1981). Congress and Its Members, Congressional Quarterly: Washington, D.C.

Frye, A., and Rogers, W. D. (1979). Linkages begin at home. Foreign Policy 35 (Summer): 49-67. Gamst, F. C., and Norbeck, E. (1976). Ideas of Culture: Sources and Uses, Holt, Rinehart, and Winston. New York.

Hamilton, L. H. (1978). Making the separation of powers work. Foreign Affairs 57,1 (Fall): 17-39. Hinckley, B. (1978). Stability and Change in Congress, Harper \& Row, New York. 
Horwitz, M., and Rabbie, J. M. (1982). Individuality and membership in the intergroup system. In H. Tajfel (ed.), Social Identity and Intergroup Relations, Cambridge University Press, Cambridge.

Hughes, B. (1978). Domestic Context of American Foreign Policy, W. H. Freeman, San Francisco.

Kessel, J. (1974). The parameters of presidential politics. Soc. Sci. Quart. (June): 8-24.

Ladd, E. C., with Hadley, C. D. (1978). Transformations of American Politics, Norton, New York.

Ladd, E. C., Jr., and Lipsett, S. M. (1971). College Generations: From the 1930s to the 1960s. Public Interest, 25: 105-109.

Leach, E. (1970). Lévi-Strauss, London: Collins.

Leach, E. (1976). Culture and Communication, MIT Press, Cambridge, Mass.

LeLoup, L., and Shull, S. A. (1979). Congress versus the excutive: The two presidencies reconsidered. Soc. Sci. Quart. 59,41 (March): 704-719.

LeLoup, L., and Shull, S. A. (1980). A comment on Sigelman. J. Politics 42.

Lévi-Strauss, C. (1963). Structural Anthropology, Doubleday, Garden City.

Lévi-Strauss, C. (1966). The Savage Mind, University of Chicago Press, Chicago.

Lévi-Strauss, C. (1969). The Raw and The Cooked, Harper \& Row, New York.

Manheim, J. B. (1979). The honeymoon's over: The news conference and the development of presidential style. J. Politics (February): 55-74.

Manning, B. (1977). The congress, the executive, and intermestic affairs: Three proposals. Foreign Affairs 55,2 (January): 306-324.

Merelman, R. M. (1984). Making Something of Ourselves: On Culture and Politics In The United States, University of California Press, Berkeley and Los Angeles.

Mueller, J. E. (1973). War, Presidents, and Public Opinion, Wiley, New York.

Polsby, N. W. (1968). The institutionalization of the U.S. House of Representatives. Am. Polit. Sci. Rev. (March): 144-168.

Rabbie, J. M. Benoist, F. Oosterbaan, H., and Visser, L. (1974). Differental power and ef fects of expected competitive and cooperative intergroup interaction on intragroup and outgroup attitudes. J. Personality Soc. Psychol. 30: 46-56.

Rabbie, J. M., and deBrey, J. H. C. (1971). The anticipation of intergroup cooperation and competition under private and public conditions. Int. J. Group Tensions 1: 230-251.

Rabbie, J. M., and Huygen, K. (1974). Internal disagreements and their effects on attitudes toward in- and outgroups. Int. J. Group Tensions 4: 222-246.

Rabbie, J. M., and Wilkens, G. (1971). Intergroup Competition and Its Effect on Intragroup and Intergroup Relations. Eur. J. Social Psychol. 1:215-234.

Rourke, J. T. (1977). Congress and the Cold War. World Affairs 139 (Spring): 259-277.

Safran, N. (1978). Israel The Embattled Ally, The Belknap Press of Harvard Univ. Press, Cambridge.

Schwartz, B. (1981). Vertical Classification: A Study In Structuralism and The Sociology of Knowledge, The Univ. of Chicago Press, Chicago.

Seckbach, F. (1974). Attitudes and opinions of Israeli teachers and students about aspects of modern Hebrew. Int. J. Sociologi. Language 1: 105-124.

Sigelman, L. (1979). A reassessment of the two presidencies thesis. J. Politics 41: 1195-1205. Sole, K. et al. (1975). Opinion similarity and helping: Three field experiments investigating the bases of promotive tension. J. Exp. Soc. Psychol. 11: 1-13.

Stein, A. A. (1976). Conflict and cohesion: A review of the literature. J. Conflict Resolution 20: $143-172$.

Tajfel, H. (1982). Social Identity and Intergroup Relations, Cambridge University Press, Paris. Truman, D. (1956). The Governmental Process, Norton, New York.

Wayne, S. J. (1978). The Legislative Presidency, Harper and Row, New York. Wildavsky, A. (1966). The two presidencies. Trans-action. IV (December): 7. 